\title{
An Innovative Approach to Hospital Sanitization Using Probiotics: In Vitro and Field Trials
}

\author{
Vincenza La Fauci ${ }^{1 *}$, Gaetano Bruno Costa ${ }^{1}$, Francesca Anastasi ${ }^{2}$, Alessio Facciolà ${ }^{2}$, Orazio Claudio Grillo ${ }^{1}$ and Raffaele Squeri ${ }^{1}$ \\ ${ }^{1}$ Department of Biomedical Sciences and Morphological and Functional Images, University of Messina, Messina, Italy \\ ${ }^{2}$ Postgraduate Medical School in Hygiene and Preventive Medicine, University of Messina, Messina, Italy
}

\begin{abstract}
Background: The nosocomial infections continue to be a problem, even in hospitals where meticulous sanitization procedures are in place. The most commonly used methods employ chemical disinfectants which carry some disadvantages.

Objective: To investigate the effectiveness of an innovative sanitization procedure using probiotic bacteria based on the principle of biological competition: Probiotic Cleaning Hygiene System (PCHS)

Methods: The study included survival tests and in vitro and field trials. The in vitro trials tested three surfaces (washbasin, floor and desk) in the absence of recontamination. Field trials were carried out in order to evaluate the efficacy of probiotics in the presence of contaminants and to study whether probiotics are able to contain pathogens over time. Samples were taken from the floor in a corridor and an inpatient room and the dispensary washbasin twice daily (pre-sanitization and post-sanitization).

Results: The in vitro tests on three surfaces, not subject to recontamination, resulted in an average reduction ranging from $92.2 \%$ to $99.9 \%$ after $24 \mathrm{~h}$. From field trials it emerged that the bacterial count was totally eliminated for Enterococcus faecalis and Candida albicans and almost $100 \%$ elimination of Pseudomonas aeruginosa, Acinetobacter baumannii e Klebsiella pneumoniae on all three surfaces after only six hours even when recontaminated. However less satisfactory results were attained for Staphylococcus aureus.

Conclusion: PCHS acts constantly and is durable over time due to the stabilization of a biofilm which is able to reduce and contain the proliferation of pathogenic microorganisms. Probiotics are therefore effective innovative products to sanitize the hospital environment.
\end{abstract}

Keywords: Hospital sanitization; Probiotics; Nosocomial infections

\section{Introduction}

Hospital infections continue to be a huge healthcare problem worldwide to which no facility, public or private, is immune. The importance of inanimate surfaces as sources of nosocomial pathogens has long been recognized/acknowledged [1-3]. Environmental sanitization is an essential and effective part of programs to prevent and control hospital infections [4]. Sanitization procedures in hospitals, combined with antibiotic prophylaxis for patients, are designed to reduce and prevent the proliferation of microorganisms. Nevertheless, nosocomial infections continue to be a problem, even in hospitals where meticulous sanitization procedures are in place. The most common environmental sanitization methods involve the use of chemical disinfectants. However, these are not without disadvantages: 1) the limited effectiveness of biocides over time (normally 20-30 minutes after application, after which microorganisms multiply exponentially); 2) the ability of microorganisms to mutate thereby annihilating the biocidal effects; 3 ) increased pollution of the natural environment arising from the massive use of chemicals that may accumulate and persist over time. The seriousness of these problems prompted us to conduct trials using an innovative sanitization technique using probiotic bacteria adopting an approach based on the principle of biological competition in which the aim is no longer to destroy the microorganisms on surfaces, but to form a biofilm to counteract the proliferation of pathogens. Probiotic studies have attracted considerable interest in recent literature, particularly in view of increased bacterial resistance [3,5-7]. These products have long been used to reduce the occurrence and/or duration of diarrhoea attacks linked to antibiotics [8,9]; and in vitro trials are now underway to assess the possibility of using probiotics outside the human body on surfaces. Some studies have focused on the potential ability of a biofilm to inhibit bacterial growth on silicone materials used in the urogenital tract $[10,11,13,15]$ oral cavity $[12,14]$ and/or other matrices $[10,16]$. Recent trials have shown that probiotic bacteria may also be used to sanitize hospital environments in order to combat the increase in nosocomial pathogens $[17,18]$. Probiotic bacteria (Probiotics in progress/PIPs) are spores of Bacillus spp, and considered to be innocuous microorganisms as, unlike disinfectants, they do not act as biocides. They are able to colonize surfaces to which they are applied, thereby effectively counteracting the proliferation and survival of other types of bacteria, including germs, by means of "competitive exclusion".

\section{Materials and Methods}

The aim of this study, carried out in the year 2013 at the University Hospital "G. Martino" in Messina (Italy), was to measure the reduction and elimination of pathogenic microorganisms using probiotics and thereby assess the effectiveness of this sanitization method. The Probiotic Cleaning Hygiene System (PCHS) was adopted for this study

*Corresponding author: Vincenza La Fauci, Department of Biomedical Sciences and Morphological and Functional Images, A.O.U. Policlinico "G Martino",Torre Biologica 1 Piano,Via Consolare Valeria,98125 MESSINA, Italy, Tel: +390902213620; Fax: +390902213351; E-mail: vlafauci@unime.it

Received April 14, 2015; Accepted May 20, 2015; Published May 30, 2015

Citation: La Fauci V, Costa GB, Anastasi F, Facciolà A, Grillo OC, et al. (2015) An Innovative Approach to Hospital Sanitization Using Probiotics: In Vitro and Field Trials. J Microb Biochem Technol 7: 160-164. doi:10.4172/1948-5948.1000198

Copyright: (c) 2015 La Fauci V, et al. This is an open-access article distributed under the terms of the Creative Commons Attribution License, which permits unrestricted use, distribution, and reproduction in any medium, provided the original author and source are credited 
conducted in the UOC laboratories for Hospital Hygiene where both in vitro and field trials were conducted.

\section{Sanitizing solution}

The probiotic-based solution contained $1 \%$ of spores $\left(30 \times 10^{6}\right.$ $\mathrm{CFU} / \mathrm{ml}$ ) of Bacillus subtilis, Bacillus pumilus and Bacillus megaterium, in addition to ionic surfactants $(0.6 \%)$, anionic surfactants $(0.8 \%)$ and enzymes (amylases 0.02\%) [18].

\section{Microorganisms and growth media used}

Strains of $S$. aureus, $P$. aeruginosa, K. pneumoniae, A. baumannii, $E$. faecalis and C. albicans, isolated from cases of nosocomial infections in hospitalized patients, were used for the in vitro trials. These strains were cultivated on the following respective media: Baird-Parker Agar, Cetrimide Agar, MacConkey Agar, Enterococcosel Agar and Sabouraud Dextrose Contact Agar.

Tryptic Soy Agar Contact (TSA) was used for the total microbial count (TMC) in field trials, in addition to the specific cultures for the same microorganisms tested in vitro. All bacterial strains were cultivated by incubation at $37^{\circ} \mathrm{C}$ for $24-48 \mathrm{~h}$.

\section{Identification of microorganisms}

Pathogenic strains were identified using API 20 NE for Pseudomonas $s p$, API $20 \mathrm{E}$ for Enterobacteriaceae microorganisms including $K$. pneumoniae and A. baumannii, API Staph for S. aureus, and API AUX $\mathrm{C}$ for Candida spp.

\section{Sanitization procedures}

Sanitization was carried out using microfibre cloths, cleaned after each use following the manufacturer's instructions. Dry surfaces were first dusted followed by wet cleaning using the probiotic liquid. The microfibre cloths were soaked in the solution and stored in clean containers until use. The sanitization steps were all carried out by the same trained staff member in order to minimize any variations in the procedure adopted. The solution used to treat surfaces was prepared in accordance with the manufacturer's instructions for application of $1.5 \times 10^{6} \mathrm{spore} / \mathrm{m}^{2}$.

\section{Survival tests}

The above microbial strains were used in survival tests to contaminate the surfaces of a wash-basin, a floor and a desk in order to assess their survival in the external environment. For this purpose, we used solutions of the microbial strains with an initial count of about $1,5 \times 10^{3} \mathrm{CFU} / \mathrm{m}^{2}$. The bacterial count on contaminated surfaces was undertaken over an eight-day period.

\section{In Vitro trials}

In vitro trials were conducted over a two-week period in order to assess how effectively probiotics were able to compete against pathogenic bacteria from the hospital environment in the absence of external factors linked to recontamination. During these tests the three surfaces (washbasin, floor and desk) were first contaminated using sterile swabs soaked with the same solutions used for the survival tests and then sanitized using PIPs. Samples of each microorganism were taken three times daily: at 8:00 (pre-sanitization), 11:00 and 14:00 (post-sanitization).

\section{Field trials}

Field trials were carried out in the Thoracic and Vascular Surgical Ward over a three-month period (May-July 2013) in order to evaluate the efficacy of probiotics in the presence of a contamination related to the daily hospital activity of healthcare workers, inpatients and relatives and to study whether probiotics are able to contain pathogens over time. Samples were taken from the floor in a corridor and an inpatient room and the dispensary washbasin twice daily, at 8:00 (pre-sanitization) and 14:00 (post-sanitization). As control group, at the same time, we carried out a comparable microbiological monitoring in similar surfaces situated in the opposite part of the ward, subjected to the same type of recontamination and sanitized using normal chemical products.

\section{Results}

\section{Survival tests}

The tests conducted to assess the survival of the same strains used for in vitro trials, showed microorganisms were still alive after 24 or 48 h. E. faecalis and $S$. aureus were particularly robust, as they continued to survive in the external environment even after four and eight days respectively. Moreover, the latter showed a continuous and progressive growth until the day 4 after which it decreased to the level at zero time (Table 1).

\section{In Vitro trials}

The in vitro tests on three surfaces, not subject to recontamination, resulted in an average reduction ranging from $92.2 \%$ to $99.9 \%$ after 24 h (Table 2).

\begin{tabular}{|l|c|c|c|c|c|c|c|c|c|c|}
\hline \multicolumn{1}{|c|}{ Strains } & \multicolumn{7}{|c|}{ Survival CFU/m $\mathbf{m}^{2} \times 10^{3} / \%$} \\
\hline & $\begin{array}{l}\text { Zero } \\
\text { Time }\end{array}$ & \multicolumn{2}{|c|}{$24 \mathrm{~h}$ CFU } & \multicolumn{2}{|c|}{$48 \mathrm{~h}$} & \multicolumn{2}{c|}{$96 \mathrm{~h}$} & \multicolumn{2}{|c|}{$192 \mathrm{~h}$} \\
\hline $\begin{array}{l}\text { Staphylococ- } \\
\text { cus aureus }\end{array}$ & 1516 & 1562 & $103 \%$ & 185 & $122 \%$ & 2500 & $165 \%$ & 1395 & $92 \%$ \\
\hline $\begin{array}{l}\text { Pseudomonas } \\
\text { aeruginosa }\end{array}$ & 1500 & 75 & $5 \%$ & 0 & 0 & 0 & 0 & 0 & 0 \\
\hline $\begin{array}{l}\text { Candida albi- } \\
\text { cans }\end{array}$ & 1583 & 7 & $0.44 \%$ & 0 & 0 & 0 & 0 & 0 & 0 \\
\hline $\begin{array}{l}\text { Enterococcus } \\
\text { faecalis }\end{array}$ & 1480 & 1156 & $78 \%$ & 474 & $32 \%$ & 89 & $6 \%$ & 0 & 0 \\
\hline $\begin{array}{l}\text { Acinetobacter } \\
\text { baumannii }\end{array}$ & 1550 & 8.4 & $0.54 \%$ & 0 & 0 & 0 & 0 & 0 & 0 \\
\hline $\begin{array}{l}\text { Klebsiella } \\
\text { pneumoniae }\end{array}$ & 1586 & 7.5 & $0.47 \%$ & 0 & 0 & 0 & 0 & 0 & 0 \\
\hline
\end{tabular}

Table 1: Survival ability in external environment of bacterial strains, isolated from cases of nosocomial infections in hospitalized patients, used for in vitro trials.

\begin{tabular}{|l|r|r|}
\hline \multicolumn{2}{|c|}{ Staphylococcus aureus } & Average \\
\hline Floor & $99.5 \%$ & \\
\hline Desk & $99.8 \%$ & $99,7 \%$ \\
\hline Washbasin & $99.8 \%$ & \\
\hline Floor & $94.8 \%$ & \\
\hline Desk & $90.9 \%$ & $92.2 \%$ \\
\hline Washbasin & $90.9 \%$ & \\
\hline & Candida albicans \\
\hline Floor & $99.7 \%$ & \\
\hline Desk & $100 \%$ & \multirow{2}{*}{$99.9 \%$} \\
\hline Washbasin & $100 \%$ & \\
\hline & Enterococcus faecalis \\
\hline Floor & $100 \%$ & \\
\hline Desk & $99.1 \%$ & \multirow{2}{*}{$99.7 \%$} \\
\hline Washbasin & $100 \%$ & \\
\hline & Acinetobacter baumannii & \\
\hline Floor & $99.5 \%$ & \\
\hline Desk & $100 \%$ & $99.8 \%$ \\
\hline Washbasin & $100 \%$ & \\
\hline & & \\
\hline
\end{tabular}

Table 2: Average \% of microbes eliminated in vitro from different surfaces after 24 $\mathrm{h}$ from the sanitation with PCHS system. 
Citation: La Fauci V, Costa GB, Anastasi F, Facciolà A, Grillo OC, et al. (2015) An Innovative Approach to Hospital Sanitization Using Probiotics: In Vitro and Field Trials. J Microb Biochem Technol 7: 160-164. doi:10.4172/1948-5948.1000198

Analysis of the individual results for each contaminated surface and each pathogenic microorganism tested showed similar results for two of the materials (wooden desk and porcelain washbasin), since after three hours only $P$. aeruginosa survived on both surfaces while E. faecalis, survived only on the wooden desk. After six hours they disappeared from both the desk and washbasin. In contrast, all microorganisms were still alive after six hours on the linoleum floor. These differences arising from the different materials (wood, porcelain, and linoleum) were eradicated after 24/30 hours when all microorganisms were destroyed on all three surfaces. Comparison of the individual microorganisms demonstrated the following percentage reductions: S. aureus, $99.4 \%$ after $3 \mathrm{~h}, 99.5 \%$ after $6 \mathrm{~h}, 99.7 \%$ at $24 \mathrm{~h}$ and total destruction at 30 h; $P$. aeruginosa, $70.2 \%$ after 3 h, $90.0 \%$ after $6 \mathrm{~h}$ and $100.0 \%$ at $24 \mathrm{~h}$; A. baumannii and K. pneumonia, $98.6 \%$ and $96.5 \%$ respectively after $3 \mathrm{~h}, 99.5 \%$ and $99.0 \%$ at $6 \mathrm{~h}$, and $99.9 \%$ and $99.5 \%$ at $24 \mathrm{~h}$ with total destruction after $27 \mathrm{~h}$; E. faecalis $96.7 \%$ after $3 \mathrm{~h}$ and total destruction after $6 \mathrm{~h}$; with similar results for C. albicans.

\section{Field trials}

Before the sanitation with PIPs, we evaluated the contamination rate of the ward by microbiological sampling using specific contact plates (not only floor, desk and washbasin but even beds, bedside tables and door handles). In these surfaces we found a contamination by $S$. aureus, E. faecalis, $P$. aeruginosa and $C$. albicans in the amount of $4 \times 10^{2} \mathrm{CFU} / \mathrm{m}^{2}, 2,5 \times 10^{2} \mathrm{CFU} / \mathrm{m}^{2}, 2 \times 10^{2} \mathrm{CFU} / \mathrm{m}^{2}$ and $0,5 \times 10^{2}$ $\mathrm{CFU} / \mathrm{m}^{2}$ respectively. After that, destruction and/or reduction of each pathogenic microorganism was achieved by sanitization using the PCHS system over the trial period (from 6 May to 30 July). While in the survival test all microorganisms were still alive after 24 or $48 \mathrm{~h}$, for E. faecalis and C. albicans the microbial count was totally eliminated (Figure 1-2). It also disappeared almost completely for $P$. aeruginosa on all three surfaces after only $6 \mathrm{~h}$, even when recontaminated (Figure 3 ). The probiotic system was equally as effective against $A$. baumannii and $K$. pneumoniae, for the first two months, while in the third month of trials six hours of contact were no longer enough to reduce bacterial

\section{Enterococcus faecalis}

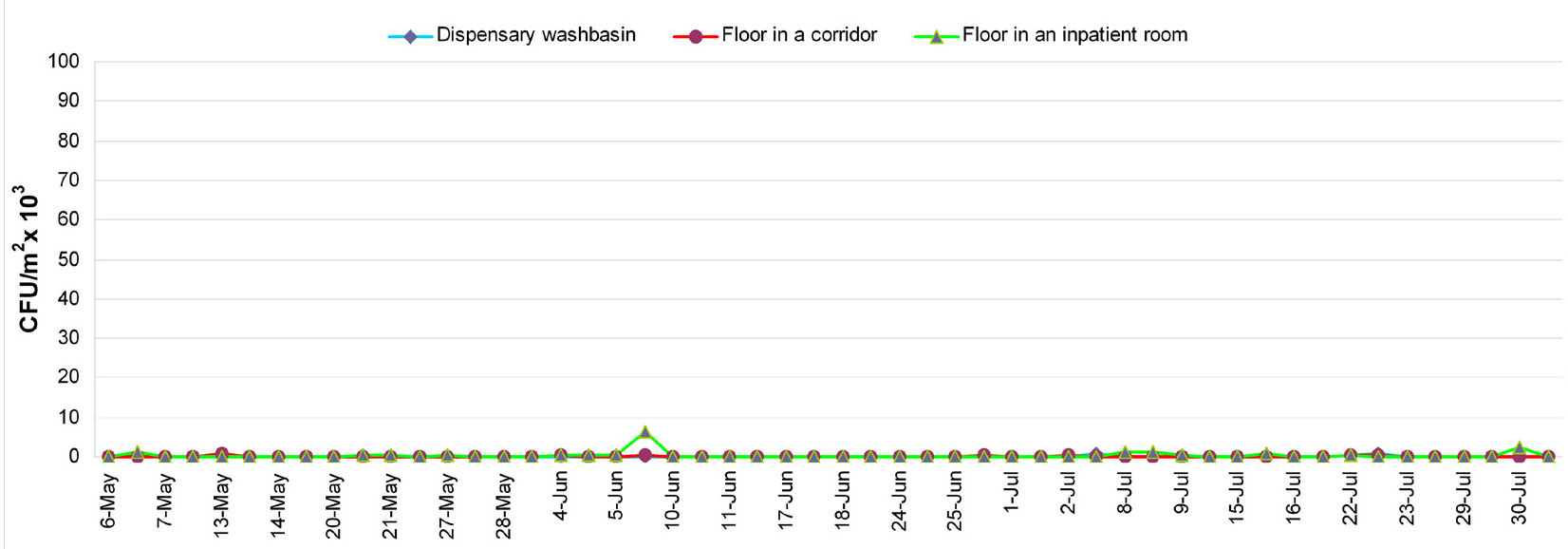

Figure 1: Field trial results for Enterococcus faecalis. This figure shows the complete elimination of the bacterial count using PIPs in the field trials.

\section{Candida albicans}

$\multimap$ Dispensary washbasin $\rightarrow$ Floor in a corridor $\rightarrow$ F Floor in an inpatient room

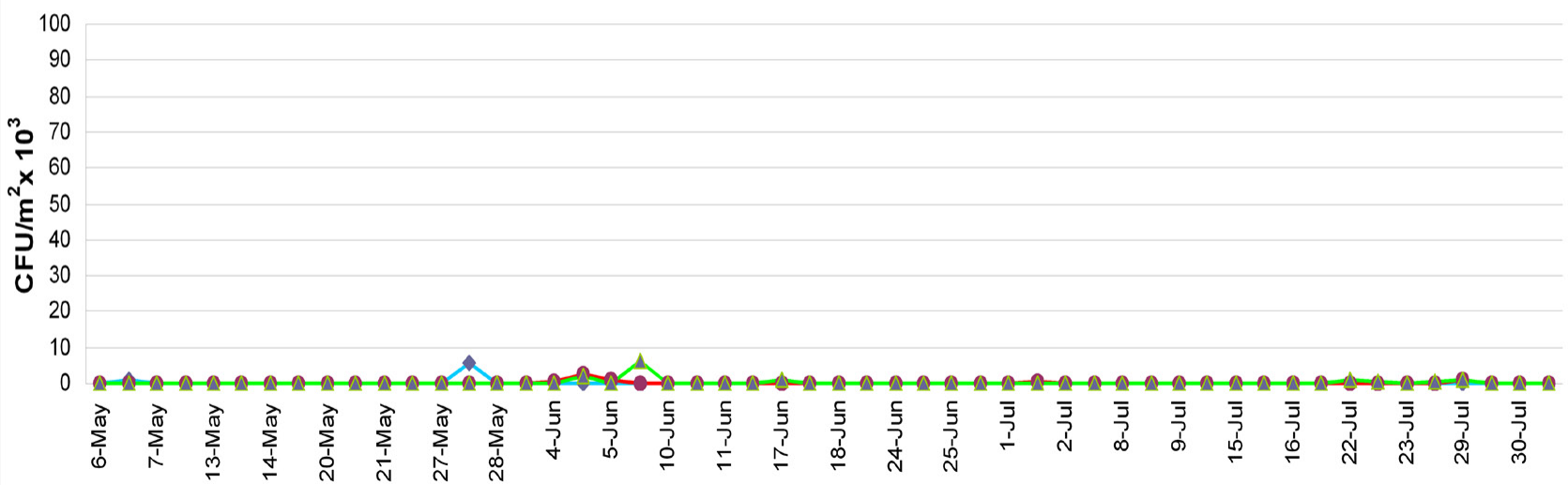

Figure 2: Field trial results for Candida albicans. Even for C. albicans, the use of PIPs completely eliminated the growth of the microorganism. 
Citation: La Fauci V, Costa GB, Anastasi F, Facciolà A, Grillo OC, et al. (2015) An Innovative Approach to Hospital Sanitization Using Probiotics: In Vitro and Field Trials. J Microb Biochem Technol 7: 160-164. doi:10.4172/1948-5948.1000198

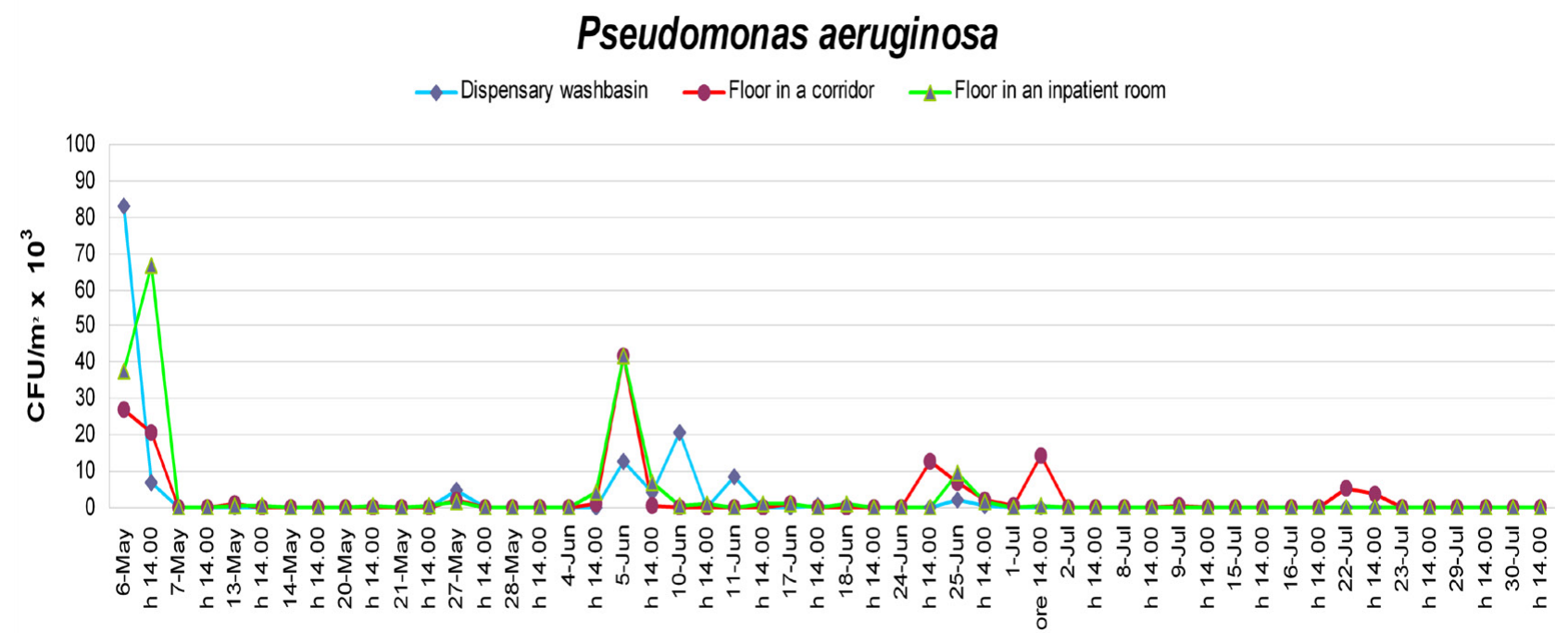

Figure 3. Field trial results for Pseudomonas aeruginosa. The figure shows that even for this hard microorganism, the use of PIPs has an important role in the control of the microbial proliferation.

\section{Acinetobacter baumanni and Klebsiella pneumoniae}

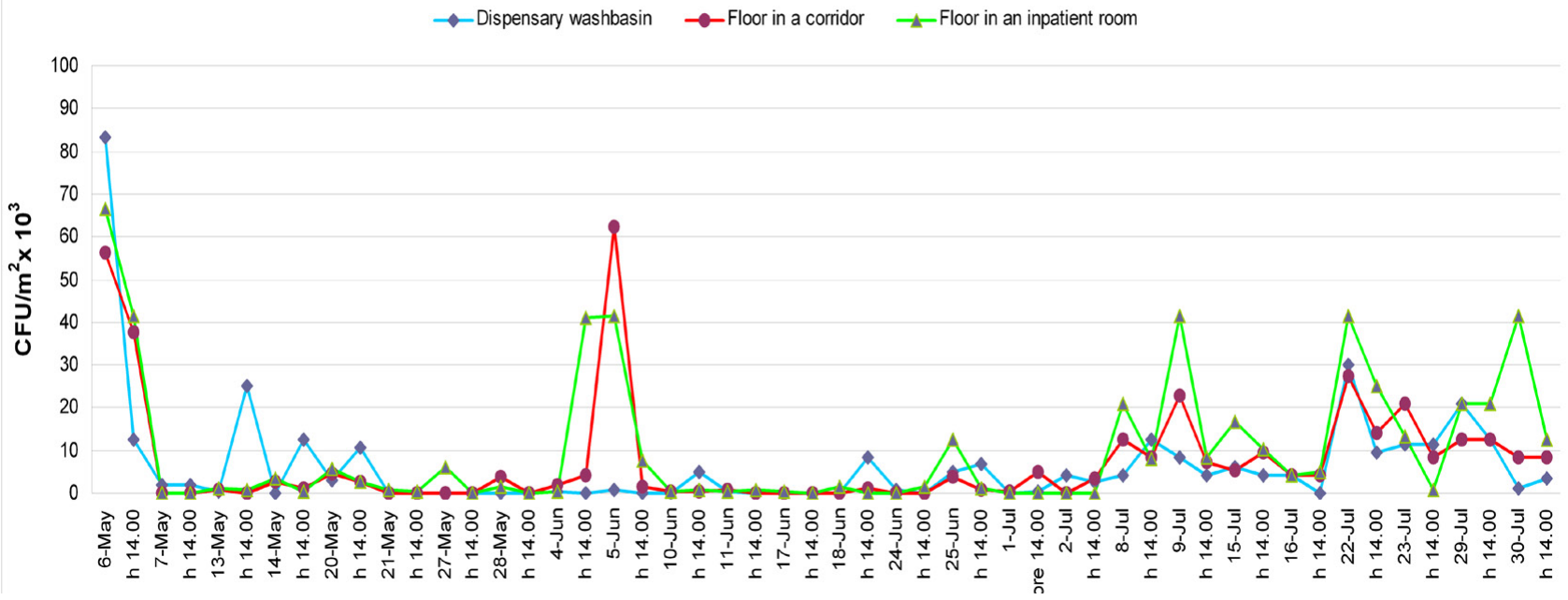

Figure 4: Field trial results for Acinetobacter baumannii and Klebsiella pneumonia. In this figure, it is evident the efficacy of the PIPs to control the microbial growth during the first two months of the trial but there was not the same results during the last month.

count significantly, although growth continued to be contained particularly for the washbasin surface (Figure 4). The efficacy of PIPs was far less evident for S. aureus (Figure 5). Indeed, sanitization using PIP following recontamination was unable to act continuously to reduce bacterial growth even three months after treatment. This was most evident on ward floor surfaces. In the control group, we observed a constant and remarkable presence of $S$. aureus, $P$. aeruginosa and $E$. faecalis, in variable concentration, for all the period of the monitoring.

\section{Discussion}

Our study confirms that probiotics are able to reduce the growth of specific pathogenic microbial species namely: $S$. aureus, $P$. aeruginosa, K. pneumoniae, E. faecalis, A. baumannii and C. albicans. The in vitro tests allowed the reduction in microbial count of the pathogens to be verified under controlled conditions, thus verifying the efficacy of PIP to combat bacteria where there is no risk of recontamination. The field trials demonstrated that the bacterial count remained low over time following sanitization despite the surfaces treated being constantly exposed to the risk of recontamination by patients, healthcare workers and visitors. The results achieved improved as time progressed but this improvement was linked to the type of material treated. It was found that sanitization was was more effective on the porcelain washbasin than the linoleum flooring. This confirms that the continuous and constant action of the PCHS system over time is the result of the stabilization of the biofilm, which is able to reduce and contain the proliferation of microorganisms.

Both the in vitro and field trials demonstrated the efficacy of these products in containing the total microbial count; and this positive effect was found to persist throughout the trial albeit with some adverse variances for A. baumannii, K. pneumoniae and S. aureus. The results obtained for these pathogens differed from the others tested as 
Citation: La Fauci V, Costa GB, Anastasi F, Facciolà A, Grillo OC, et al. (2015) An Innovative Approach to Hospital Sanitization Using Probiotics: In Vitro and Field Trials. J Microb Biochem Technol 7: 160-164. doi:10.4172/1948-5948.1000198

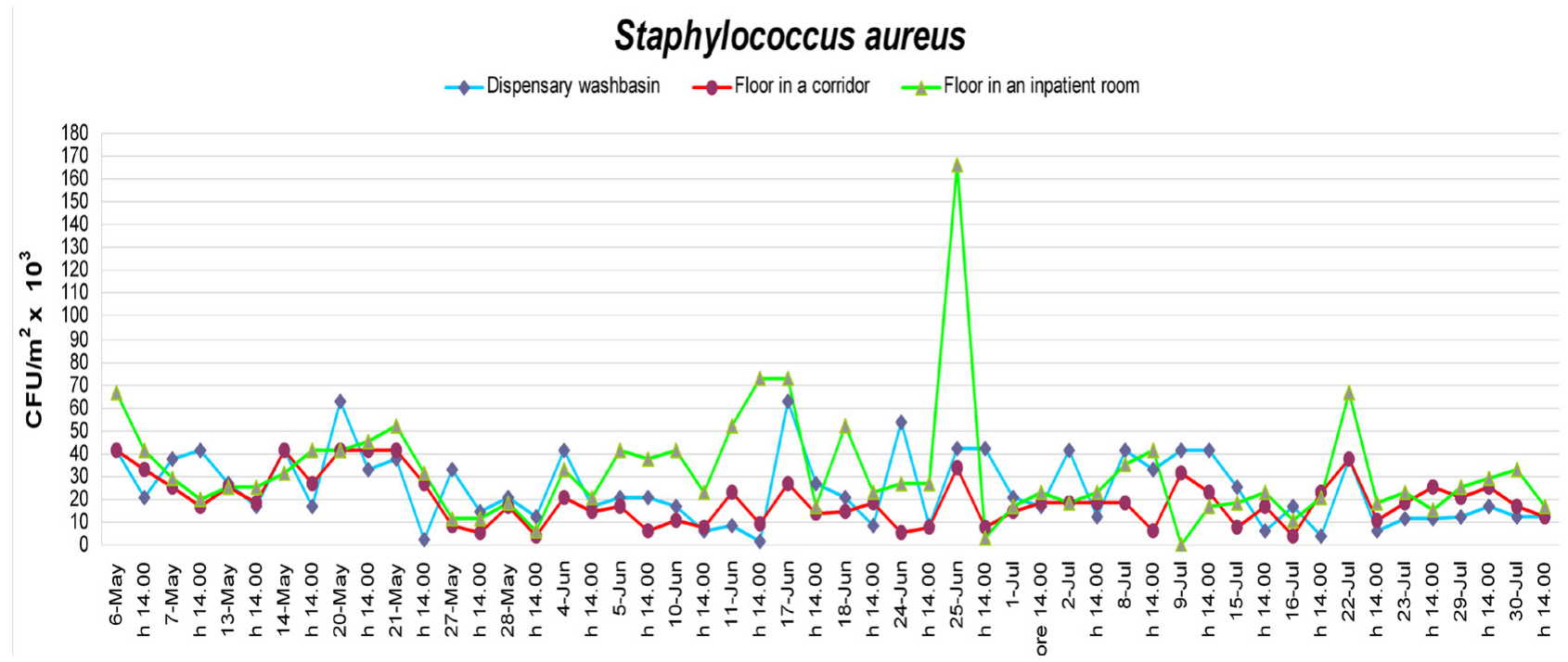

Figure 5: Field trial results for Staphylococcus aureus. In this figure is shown that the efficacy of PIPs was far less evident for this microorganism.

the probiotic biofilm was unable to compete effectively for the entire duration of the trials undertaken. In the case of $S$. aureus this finding is probably linked to its greater resistance and vigour in the environment; as shown by the survival tests.

Probiotics are ecological, easy to use and biodegradable. They render the environment hygienically stable and are able to survive on and colonize non biological surfaces, combatting the proliferation of other bacteria. In this study they were also found to perform well on surfaces in the hospital environment that are subject to regular recontamination. Probiotics are therefore effective innovative products for sanitizing the hospital environment and constitute a valid "green" alternative to the chemical disinfectants used up to now. However, further trials are necessary to test the product on surfaces which expose hospitalized patients to the greatest risks of infection.

\section{References}

1. Otter JA, Yezli S, French GL (2011) The role played by contaminated surfaces in the transmission of nosocomial pathogens. Infect Control Hosp Epidemiol 32: $687-699$.

2. Dancer SJ (2009) The role of environmental cleaning in the control of hospitalacquired infection. J Hosp Infect 73: 378-385.

3. Squeri R, Grillo OC, La Fauci V (2012) Surveillance and evidence of contamination in hospital environment from meticillin and vancomycin-resistant microbial agents. J Prev Med Hyg 53: 143-145

4. Dancer SJ (2004) How do we assess hospital cleaning? A proposal for microbiological standards for surface hygiene in hospitals. J Hosp Infect 56: 10-15.

5. Oudhuis GJ, Bergmans DC, Verbon A (2011) Probiotics for prevention of nosocomial infections: efficacy and adverse effects. Curr Opin Crit Care 17 487-492.

6. Sanders ME, Guarner F, Guerrant R, Holt PR, Quigley EM, et al. (2013) An update on the use and investigation of probiotics in health and disease. Gut 62: 787-796

7. Gill HS, Guarner F (2004) Probiotics and human health: a clinical perspective Postgrad Med J 80: 516-526.

8. Goossens D, Jonkers D, Stobberingh E, van den Bogaard A, Russel M, et al. (2003) Probiotics in gastroenterology: indications and future perspectives. Scand J Gastroenterol Suppl : 15-23.
9. Applegate JA, Fischer Walker CL, Ambikapathi R, Black RE (2013) Systematic review of probiotics for the treatment of community-acquired acute diarrhea in children. BMC Public Health 13 Suppl 3: S16.

10. Falagas ME, Makris GC (2009) Probiotic bacteria and biosurfactants for nosocomial infection control: a hypothesis. J Hosp Infect 71: 301-306.

11. Rodrigues L, van der Mei H, Banat IM, Teixeira J, Oliveira R (2006) Inhibition of microbial adhesion to silicone rubber treated with biosurfactant from Streptococcus thermophilus A. FEMS Immunol Med Microbiol 46: 107-112.

12. Rodrigues L, van der Mei HC, Teixeira J, Oliveira R (2004) Influence of biosurfactants from probiotic bacteria on formation of biofilms on voice prostheses. Appl Environ Microbiol 70: 4408-4410.

13. Velraeds MM, van de Belt-Gritter B, Busscher HJ, Reid G, van der Mei HC (2000) Inhibition of uropathogenic biofilm growth on silicone rubber in human urine by lactobacilli--a teleologic approach. World J Urol 18: 422-426.

14. van der Mei HC, Free RH, Elving GJ, Van Weissenbruch R, Albers FW, et al. (2000) Effect of probiotic bacteria on prevalence of yeasts in oropharyngeal biofilms on silicone rubber voice prostheses in vitro. J Med Microbiol 49: 713 718

15. Velraeds MMC, Van der Mei HC, Reid G, Busscher HJ (1997) Inhibition of initial adhesion of uropathogenic Enterococcus faecalis to solid substrata by an adsorbed biosurfactant layer from Lactobacillus acidophilus. Urology 49 : 790-794.

16. Busscher HJ, van Hoogmoed CG, Geertsema-Doornbusch GI, van der Kuijl-Booij M, van der Mei HC (1997) Streptococcus thermophilus and its biosurfactants inhibit adhesion by Candida spp. on silicone rubber. Appl Environ Microbiol 63: 3810-3817.

17. Vandini A Frabetti A, Antonioli P Platano D, Branchini A et al (2014) Reduction of the Microbiological Load on Hospital Surfaces Through ProbioticBased Cleaning Procedures: A New Strategy to Control Nosocomial Infections. J Microbiol Exp 1: 00027.

18. Vandini A, Temmerman R, Frabetti A, Caselli E Antonioli P et al. (2014) Hard surface biocontrol in hospitals using microbial-based cleaning products. PLoS One 9: e108598. 